\title{
Língua escrita e consciência histórica em produções de crianças e adolescentes*
}

Maria Lima ${ }^{* *}$

\section{RESUMO}

As concepções empiristas de aprendizagem no ensino de História centram-se, via de regra, na transmissão de fatos e conceitos por meio da exposição do conteúdo e dos exercícios de fixação. No ensino da língua escrita, privilegiam o domínio do código e da ortografia, centrando-se mais nas estruturas do que nos usos. Opondo-se a isso, o presente artigo traz alguns dos elementos envolvidos com a compreensão dos processos cognitivos presentes no desenvolvimento da consciência histórica e da competência narrativa, calcada nas reflexões de Vygotsky e Bakhtin sobre a relação palavra e consciência, e de Rüsen sobre a consciência histórica enquanto aprendizagem. 0 corpus da investigação foi constituído por 134 produções textuais de 67 estudantes $\left(29\right.$ da $5^{\text {a }}$ série e 38 da $8^{a}$ série do Ensino Fundamental) de uma escola municipal de São Paulo, os quais foram convidados a escrever e reescrever um texto considerando uma problemática social.

Palavras-chave: Produção textual, Ensino de história, Consciência histórica, Didática da história.

\section{Introdução}

Nas aulas de História, as atividades que envolvem a produção escrita do estudante, na grande maioria do tempo, são extremamente escolarizadas e descontextualizadas, tendo como único destinatário o professor que lê para corrigir e não para entrar em contato com o que o estudante pensa ou como ele expressa lingüisticamente o que pensa.

0 que prevalece é um olhar incapaz de articular a possibilidade de aprender a língua e construir conhecimento, ou mesmo de usar a língua e "manipular" criticamente os conhecimentos adquiridos. 0 estudante escreve

\footnotetext{
* Esse artigo é derivado da tese de doutoramento intitulada Relações entre língua escrita e conciência bistórica produções de crianças e adolescentes. Defendida na Faculdade de Educação da USP em 2007.

** Trabalha com formação de professores, equipe técnica e funcionários de escola. Email: maria-lima@uol.com.br.
} 
unicamente para ser corrigido, porque não se concebe (e, portanto, pouco se trabalha) a língua como instrumento que permite relacionar, ampliar, contrapor, hipotetizar, argumentar, definir, problematizar conteúdos. Além disso, o professor especialista desconhece o potencial que esta modalidade lingüística possui como mediadora no desenvolvimento das funções psicológicas superiores e as relações que existem entre a escrita e o desenvolvimento da consciência. 0 que agrava ainda mais esse quadro é a desconsideração da função comunicativa da linguagem que se realiza na relação efetiva entre falantes, sujeitos envolvidos no ato comunicativo, e os discursos por ele produzidos.

0 modo como o indivíduo lança mão de diferentes práticas da língua escrita, acessa diferentes campos de conhecimento e participa do universo cultural está diretamente ligado às experiências vividas conferindo-se um certo grau de letramento. Essa condição explica o seu locus na sociedade, carregado de valoração social e determinante da possibilidade de ser em um determinado meio.

Nesse contexto, a democratização do saber implica a adesão a formas de produção e transmissão do conhecimento da cultura ocidental, industrial e urbana. Além disso, é possível afirmar que "não existe nenhum conhecimento que não esteja materializado numa linguagem, uma vez que o pensamento conceitual é lingüístico"(FIORIN, 2002, p.56).

Tais evidências tornam pertinente a aproximação das questões relacionadas à aprendizagem da escrita àquelas do ensino de História. Como forma de contribuir para a superação da concepção empirista de ensino/aprendizagem, que reduz a História ao domínio de conceitos, fatos, feitos e datas, e o ensino da língua à aquisição do código da escrita, sua natureza alfabética e suas regras, o objetivo do presente artigo é fornecer alguns elementos para uma melhor compreensão dos processos cognitivos inerentes à relação entre a aprendizagem da língua escrita e o desenvolvimento da consciência histórica.

\section{Língua escrita: sociedade, pensamento e consciência}

Associada à consolidação do Capitalismo como sistema econômico hegemônico, a escrita ensinada pela instituição escolar teve importante papel na divulgação de um imaginário nacionalista no decorrer de toda a Idade Contemporânea. A comunidade imaginada da cristandade cedeu lugar, gradativamente, ao ideário do Estado Nacional, que se configurou com base em diversos fatores, dentre eles, o da revolução provocada pela descoberta da imprensa. 
Ao longo do século XIX, com a afirmação da burguesia e a consolidação do Estado Nacional por diversos povos europeus, o discurso iluminista sobre a importância e a necessidade de tornar universal o acesso ao saber transformou a aprendizagem da leitura e da escrita em condição sine qua non. Gradualmente, ler e escrever tornaram-se qualificações imprescindíveis para diversas profissões e, cada vez mais, para a própria inserção social e política dos indivíduos, definindo-os, em última instância, como cidadãos. A necessidade de popularização do ler e do escrever surgiu em meio ao processo de fortalecimento das instituições que garantiriam a expansão do sentimento de patriotismo necessário à consolidação do Estado Nacional nos moldes europeus. E foi nesse contexto e com esta tarefa que surgiu a escola nos moldes em que a conhecemos ainda nos dias de hoje, concebida como a principal instituição de ensino e, particularmente, do ensino da língua escrita.

A identidade nacional, componente essencial do ideário da nação, instituiu-se calcada no tripé: subjetividade, tempo e espaço. Dito em outras palavras, a identidade engendrou-se na qualificação do grupo político ao qual se pertence (o "nós", que na modernidade, se expressa na nação); na memória, na história, na tradição que sustentam a unidade desse grupo; e, por último, no espaço no qual ele se inscreve e existe(CERRI, 2000). Para essa tarefa contribuiu também o ensino da História e da Geografia.

Assim, desde sua conformação ao projeto político-ideológico da burguesia européia oitocentista, a tarefa da instituição escolar tem sido a transmissão de valores culturais e de representações provenientes da cultura dominante cujo fim último era, através da instauração de padrões nas formas de pensar, subordinar os grupos dissidentes e as classes populares. Para isso contribuía o ensino da Língua Materna, com destaque para o papel civilizatório que a língua escrita desempenhou nesse contexto.

A crença na superioridade da escrita subsidiou a idéia de que essa prática de linguagem promoveria o desenvolvimento cognitivo por possibilitar maior abstração. Por isso, ela teria permitido o desenvolvimento científico nos patamares que a Era Moderna havia visto. No entanto, nenhum trabalho científico identificou uma relação clara entre o pensamento e a escrita. Ao contrário, há estudos recentes afirmando que os processos cognitivos - antes entendidos como dependentes da escrita, como a memorização, a reflexão e a composição de textos ou o pensamento científico - são, na realidade, invenções do discurso oral(OLSON, 1997). 
A relativização do poder da escrita para as sociedades ocidentais tem sido um movimento importante por abrir a possibilidade de se compreender de maneira mais pertinente o papel dessa prática de linguagem no desenvolvimento cognitivo e em sua relação com a consciência.

A escrita é um signo mediador do desenvolvimento humano, característica que nos permite visualizar os processos cognitivos presentes em suas relações com o desenvolvimento da consciência histórica. Enquanto mediador externo, essa modalidade lingüística favorece a organização do pensamento para se lidar com coisas do mundo imediato, concreto, intermediando as relações entre os homens e permitindo que o indivíduo adquira formas mais complexas de se relacionar com o mundo que o cerca. Por ser utilizada como marca externa que auxilia o ser humano em tarefas que exijam memória ou atenção, a escrita constitui-se como representação da realidade, referindo-se a elementos ausentes do espaço e do tempo presentes, prestando-se, além disso, como uma ferramenta que ajuda a manipular a palavra(OLIVEIRA, 1993; REG0, 2001) para fins de comunicação. Enquanto mediador interno, a escrita favorece as possibilidades de pensar, organizar, lembrar, planejar, arquivar etc., cuja ocorrência promove uma transformação no modo do sujeito operar sobre o mundo, modificando-se também sua autoimagem e sua maneira de relacionar-se socialmente. Ao se revelar como instrumento interno, a língua escrita, em seu aspecto mediador e semiótico, pode ser compreendida, simultaneamente, como um espaço de manifestação e constituição da consciência.

Vygotsky levou em conta que as palavras têm um papel central não só no desenvolvimento do pensamento, mas também na evolução da consciência como um todo, sendo uma palavra considerada um microcosmo da consciência humana (AGUIAR, 2000). A relação mediada entre pensamento e linguagem inclui a palavra como signo, instrumento convencional de natureza social. A analogia básica entre signo e instrumento, segundo Vygotsky, repousa na função mediadora que os caracteriza. Apoiando-se em Hegel e em Marx, o autor afirma que o uso de signos pode ser entendido como atividade mental devido ao fato de afetar o comportamento humano(VYGOTSKY, 2000). Vygotsky, que considera os signos como meio de contato com o mundo exterior, consigo mesmo e com a própria consciência (FREITAS, 2002), aponta duas mudanças qualitativas no seu uso: a) a utilização de marcas 
externas transforma-se em processos internos de mediação, mecanismo que chamamos de processo de internalização; b) o desenvolvimento de sistemas simbólicos que organizam os signos de maneira mais complexa em sistemas de representação(OLIVEIRA, 1993). Esses sistemas de representação são socialmente dados e possibilitam ao indivíduo a apreensão do real de maneira mais sistematizada, potencializando sua ação sobre ele.

Além de Vygotsky, Bakhtin, em seus estudos sobre a linguagem, também se preocupou em examinar aspectos semióticos da consciência tomando como base o materialismo dialético. De maneira geral, seu pensamento apresenta uma preocupação com a linguagem inserida num contexto sócio-histórico de uso, pois, como ele mesmo aponta, "o locutor serve-se da língua para suas necessidades enunciativas concretas (para o locutor, a construção da língua está orientada no sentido da enunciação da fala)"(BAKHTIN, 1986, p.92). Toda relação social é entendida como ideológica e tudo o que é ideológico possui um significado e remete a algo material que está fora de si mesmo. Nesse sentido, tudo o que é ideológico é um signo e, dessa forma, sem signos não existe ideologia. 0 locutor serve-se, em especial, da palavra, a qual possui uma característica ideológica que a torna signo para a consciência.

Cada signo ideológico não é apenas um reflexo da realidade, mas também um fragmento material da mesma realidade e um fenômeno do mundo exterior que se apresenta como a encarnação material da consciência. "A consciência só se torna consciência quando se impregna de conteúdo ideológico (semiótico) e, conseqüentemente, somente no processo de interação social".(BAKHTIN, 1986, p.34). 0 homem, fora das condições sócio-econômicas objetivas, fora da sociedade, não tem consciência(FREITAS, 2002).

Dentre esses materiais, num contexto discursivo, a palavra, fenômeno ideológico por excelência, é o material privilegiado da comunicação na vida cotidiana. E a palavra não é só importante por estar vinculada aos processos de produção, mas também por se constituir como material semiótico da vida interior(BAKHTIN, 1986).

As considerações de Vygotsky e Bakhtin em torno da relação palavra e consciência são importantes neste estudo na medida em que nos permitem vislumbrar aspectos dos processos cognitivos que podem estar presentes na relação língua escrita e consciência histórica. Para esclarecer mais alguns 
elementos dessa relação, importa aqui apresentar a concepção de consciência histórica, que assumimos neste trabalho, e a partir de que referenciais a compreendemos como um processo de aprendizagem.

\section{Consciência histórica como aprendizagem}

Tomamos como referencial o conceito de consciência histórica elaborado por RÜSEN(1992, 1993, 1994, 2001a, 2001b, 2004, 2005). Para esse autor, a ação intencional do homem é fundamental à sua existência. Dialeticamente, ao satisfazer uma necessidade, o ser humano cria outra que lhe é nova, desconhecida e que, simultaneamente, o move no sentido de apreender a novidade. Assim, o processo de compreender sua experiência no tempo é sempre novo e the possibilita a constituição de um arsenal cognitivo que subsidia sua projeção no futuro. Por isso também é intencional e tem um sentido.

A perspectiva do autor abre horizontes de análise para o ensino de História e amplia o olhar sobre a aprendizagem na medida em que o estudante não é tomado, a priori, como um ser "sem consciência", mas como alguém que possui uma maneira própria de enxergar a relação entre o presente, o passado e o futuro. Tomada em si, trata-se de uma construção que, por princípio, não é melhor nem pior daquela do especialista. 0 ensino de História passa, então, a ter como principal tarefa criar possibilidades de desenvolvimento da consciência histórica do estudante. Mas para isso é preciso esclarecer duas questões básicas: como essa consciência se manifesta? E, uma vez submetida ao processo do ensino, de que maneira avaliar se houve transformação?

Em busca de resposta a estas questões, Rüsen afirmou que, quando a consciência histórica é compreendida como aprendizagem, a competência narrativa configura-se como seu elemento essencial. Tal competência é definida como a habilidade de a consciência humana realizar procedimentos que dão sentido ao passado, tornando efetiva uma orientação temporal da vida prática no presente através da recordação da realidade passada(RÜSEN, 1992). Nessa perspectiva, a possibilidade de narrar é fundamental uma vez que a narrativa histórica é mais do que um modo específico da historiografia. Intérpretes contemporâneos como RICOUER(1994) apresentam a narrativa histórica como um procedimento mental básico que dá sentido ao passado com a intenção de orientar a vida prática no tempo(RÜSEN, 1993). 
As relações entre tempo e narrativa demonstram que a compreensão do tempo é uma produção lingüística. Simultaneamente, há um movimento em que as operações discursivas envolvidas na narrativa implicam também um processo constitutivo da compreensão do mundo pelo homem, envolvendo, ainda, a constituição do próprio ser.

Sendo a consciência histórica uma operação mental de constituição de sentido, a competência narrativa configura-se como sua competência específica e essencial, a qual se manifesta pela função, pelo conteúdo e pela forma. A função pode ser chamada de "competência para a orientação histórica"; o conteúdo seria a "competência para a experiência histórica", enquanto que a forma se configura na "competência para a interpretação histórica".

A competência de orientação é a capacidade de compreender que o passado é uma fonte de referência para o presente, sendo possível buscar nele elementos que permitam compreender melhor o presente e elaborar planos de ação para o futuro. A competência da experiência é a capacidade de um ser humano compreender o passado em sua densa existência. É a possibilidade de entender que pessoas viveram em outro tempo, fizeram opções, constituíram experiências que são diferentes das nossas. Compreender a experiência do passado significa diferenciá-la daquela do presente, reconhecendo suas especificidades e estabelecendo uma relação de empatia com ele. 0 olhar para essas experiências resulta na construção de interpretações sobre o passado que guiam a análise do presente e as perspectivas (e representações) de futuro que necessariamente emergem. A interpretação, quando relacionada à dimensão da vida prática, refere-se à capacidade do ser humano em atribuir significados às transformações sofridas no tempo, imputando sentido à experiência de sua existência temporal. A competência de interpretação abre possibilidades de agir o que, em última instância, é o grande objetivo da relação humana com o passado.

Nessa perspectiva, a aprendizagem histórica é compreendida como um processo de tomada de consciência de fatos que ocorre entre dois pólos: por um lado, a compreensão dos pretextos objetivos das mudanças vividas pelas pessoas e por seu mundo (objetivação); por outro, a compreensão de si próprio e da sua própria existência no tempo (subjetivação). Naturalmente, durante 0 processo de aprendizagem, o sujeito aprendente tem a tendência a associar suas experiências aos dados e análises históricas para compreendê-los. Esse 
processo simultâneo se dá no corpo da narrativa histórica, espaço onde a vida humana ganha existência temporal, onde se articulam o não-ser e o vir-a-ser, e onde se efetiva a função de orientação da História.

Quando a aprendizagem é compreendida como uma qualidade específica dos procedimentos mentais da consciência histórica, a quantidade de conhecimentos que o sujeito detém não é um critério considerado adequado para avaliar seu desenvolvimento. Por outro lado, quando o sujeito aprende História para utilizá-la na análise de aspectos de sua vida prática, compreender a experiência do tempo, interpretando-a na forma de história, é possível dizer que houve aprendizagem, pois houve desenvolvimento da consciência histórica.

É importante ressaltar que a compreensão do passado - que se dá na forma de narrativa e, portanto, se constitui na competência narrativa - está envolta nas deliberações morais que conectam passado, presente e futuro em torno de uma realidade visível ao sujeito que a enuncia. A necessidade de tomar decisões frente a uma série de situações leva-nos a recorrer a nosso sentido de responsabilidade e à nossa consciência. Na avaliação dessas situações, ativamos nossos valores e os consideramos na relação com o contexto para podermos constituir uma ação que seja coerente. Nesse âmbito, a consciência histórica torna-se um pré-requisito necessário, pois funciona como um modo específico de orientação em situações reais da vida presente (RÜSEN, 1992).

Para estabelecer os parâmetros de avaliação de desenvolvimento e transformação da consciência histórica, recorremos à tipologia elaborada por RÜSEN(1992, 2004, 2005) justamente com a intenção de possibilitar a compreensão da consciência histórica como aprendizagem.

0 autor aponta quatro tipos de consciência que não podem ser tomadas nem numa perspectiva evolutiva, nem como mutuamente excludentes: a tradicional, a exemplar, a crítica e a genética. Elas podem ser encontradas não só entre diferentes pessoas que vivem numa mesma época, mas na consciência de uma só pessoa. 0 quadro a seguir possibilita uma visão geral das características dos tipos de consciência histórica: 


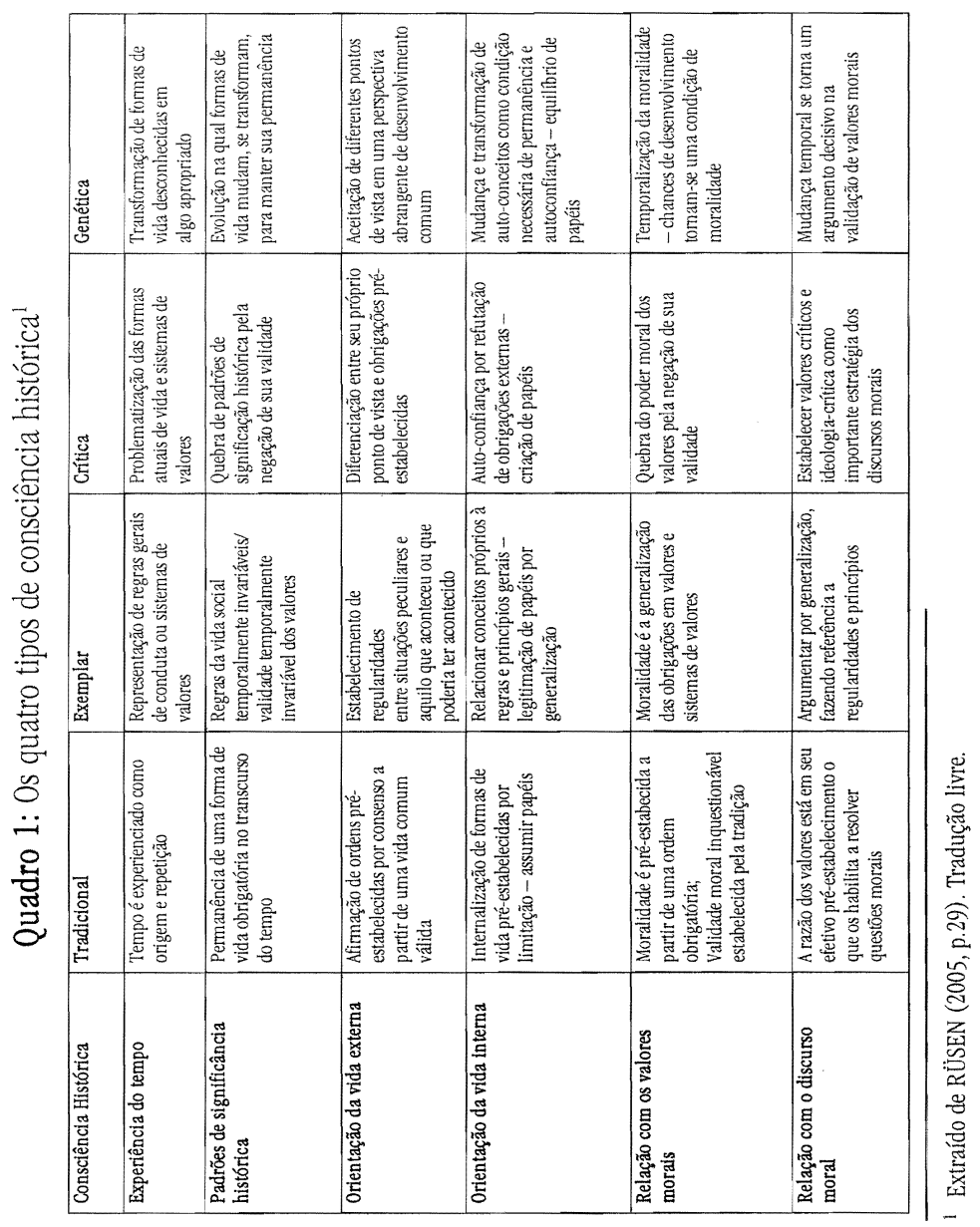




\section{A produção textual do estudante como espaço de dialogia}

0 corpus do presente trabalho é constituído por 134 produções textuais de 67 estudantes coletadas ao longo de 3 encontros, no período compreendido entre agosto e outubro de 2006. Foi realizado na Escola Municipal de Ensino Fundamental João XXIII, situada no jardim João XXIII, bairro do Butantã, na cidade de São Paulo.

No primeiro encontro com os estudantes, de 11 e 16 anos, o objetivo era apresentar uma situação motivadora da escrita a partir da qual seria constituído um processo de elaboração textual a ser retomado em outras duas sessões.

Considerando que conhecer a experiência do passado, num contexto em que existe uma demanda da vida presente, é o que dá sentido à aprendizagem em História, procuramos estruturar uma situação motivadora para a expressão de aspectos da consciência histórica pela busca das razões eventualmente subjacentes a um acontecimento recente. Nesse sentido, os escritos dos alunos deveriam constituirse em espaços de produção lingüística, fazendo emergir fragmentos da consciência histórica. Escolhemos, então, o caso de denúncia de discriminação racial feita pelo jogador do time de futebol do São Paulo Futebol Clube conhecido pelo apelido de "Grafite". 0 episódio teve lugar no dia 13.04.05², num jogo entre aquele time e 0 Quilmes, time argentino, momento em que, segundo "Grafite", o jogador De Sábato o xingou de "macaco". 0 caso, amplamente divulgado pela mídia nacional e internacional, catalisou um debate em torno do preconceito racial e estendeu-se por meio ano.

A agressão desferida por De Sábato contra "Grafite" apareceu, no amplo debate que se instaurou, associada às atitudes de preconceito e discriminação racial consideradas parte do cotidiano em muitos lugares do mundo, incluindo o Brasil. Tanto a atitude de agressão, quanto aquela de defesa do jogador "Grafite" foram debatidas pela população local e mundial. A proporção que 0 episódio assumiu entre os brasileiros e a longevidade de sua discussão podem ser explicadas porque o fato reacendeu a tradicional "rivalidade" Brasil/

\footnotetext{
2 A coleta dos dados ocorreu um ano e meio após o incidente. Optamos por mantê-la no desenho, pois fez parte do estudo piloto realizado em 2005, o qual demonstrou a adequação do tema aos propósitos do estudo. Importante ressaltar que os alunos não tiveram dificuldades para se lembrar do episódio, mesmo depois de tanto tempo.
} 
Argentina. Do ponto de vista simbólico, o "duelo" ocorreu numa "arena" que é como podemos olhar para o campo de futebol, um dos espaços de expressão da nacionalidade onde se torna forte o sentimento de unidade e de identificação no interior dos grupos participantes (CERRI, 2000). A rejeição à atitude discriminatória de um argentino em solo nacional ressaltou um sentimento de solidariedade entre os brasileiros.

Iniciamos o trabalho, no primeiro encontro, conversando com os estudantes sobre o episódio envolvendo o jogador "Grafite" e sua atitude de denúncia. Alguns dados foram fornecidos oralmente pela pesquisadora que incitou os estudantes a rememorar a situação. Após a conversa inicial, solicitamos a produção de um texto (denominada $P 1$ ), a partir da seguinte consigna:

Escreva um texto contando para mim se você já viveu ou presenciou alguma situação parecida com esta que acabamos de conversar. Nesse texto, também me explique por que fatos como o vivido por "Grafite" e esse que você relatou acontecem. Por fim, escreva o que você acha que precisaria ser feito para que a gente possa lidar com situaç̃oes como essas.

Ao considerarmos que a produção, enquanto atividade lingüística, é um discurso construído na relação interlocutiva, lemos o primeiro texto produzido com a intenção de elaborar uma problematização que se configurasse como uma contrapalavra.

Se no primeiro encontro o objetivo era a produção de um texto individual que pudesse fazer emergir livremente aspectos da competência narrativa do sujeito, no segundo, a intenção foi motivar a transformação de aspectos da narrativa, bem como contribuir para uma maior explicitação de fragmentos da consciência histórica, a partir de uma intervenção formalmente planejada. Assim, com base nos dados que emergiram da leitura de P1, selecionamos cinco textos que "dialogariam" com as concepções dos estudantes. Ao mesmo tempo, consideramos que eles deveriam servir de modelo de estratégias do dizer que potencializariam a expressão de suas idéias, contribuindo também com sua expansão.

No segundo encontro, chamado por nós de momento de ampliação da reflexão bistórica e lingüistica, os textos escolhidos foram lidos em voz alta 
pela pesquisadora para os estudantes. Antes da leitura, foi esclarecido que 0 objetivo da atividade era colher elementos que pudessem ser acrescentados à P1, a qual seria reescrita na sessão seguinte. Compreendido como uma preparação para a reescrita, esse momento privilegiou o debate entre os estudantes a partir do comentário de alguns textos. Inserimos neste artigo dois dos textos apresentados e os seus respectivos objetivos, a título de exemplo:

\section{Quadro 2: Dois dos cinco textos provocadores apresentados aos estudantes no segundo encontro}

\begin{tabular}{|c|c|}
\hline Texto apresentado & 0 que se pretendeu provocar \\
\hline \multirow{3}{*}{$\begin{array}{l}\text { Texto } 1 \\
\text { Depoimentos: } \\
\text { "Se estou numa rua caminhando e vem em minha } \\
\text { direção um branco e um negro, nunca penso que eu } \\
\text { vou ser assaltada pelo branco (...). Sempre penso que o } \\
\text { negro vai me atacar, sabe, acho que é uma visão da } \\
\text { mídia mesmo. Acho que não nasci com isso na minha } \\
\text { cabeça... A questão do marginal, para mim, está ligada } \\
\text { ao negro. Sempre, isso é verdade." } \\
\text { "No dia-a-dia o negro só é visto como ladrão, menor } \\
\text { abandonado e marginal." (extraído de Bento, M.A.S. } \\
\text { (2001) Cidadania em preto e branco - discutindo } \\
\text { as relações raciais. São Paulo: Ática, pág.21) }\end{array}$} & Reflexão sobre o fato de que as idéias são construções \\
\hline & \\
\hline & $\begin{array}{l}\text { Aspectos lingüísticos: } \\
\text { No } 1^{\circ} \text {. Relato, a autor comenta uma situação } \\
\text { hipotética para refletir sobre a origem social de suas } \\
\text { idéias. } 0 \quad 2^{\circ} \text { relato ressalta o "só" } \\
\text { indicando/subentendo que há outras formas de se ver } \\
\text { o negro. } \\
\text { Tem uma linguagem informal, com várias marcas de } \\
\text { oralidade, aproximando-se dos relatos feitos pelos } \\
\text { estudantes. }\end{array}$ \\
\hline \multirow{2}{*}{$\begin{array}{l}\text { Texto 2: } \\
\text { Hoje em dia, as pessoas discriminam os negros com } \\
\text { base em teorias que foram inventadas há muito tempo. } \\
\text { No século XIX, pensadores franceses utilizaram os } \\
\text { estudos de Charles Darwin para explicar porque alguns } \\
\text { povos eram inferiores e outros superiores. Diziam que } \\
\text { alguns eram fracos e outros fortes. Os fortes tinham } \\
\text { características que os tornavam superiores e os } \\
\text { autorizava a mandar. } \\
\text { Daí dá pra concluir o que aconteceu: os povos fortes } \\
\text { foram associados aos brancos europeus e os povos } \\
\text { fracos aos negros e não europeus. Essa é a base da } \\
\text { teoria do racismo. (Adaptado de Bento, M.A.S. (2001) } \\
\text { Cidadania em preto e branco - discutindo as } \\
\text { relações raciais. São Paulo: Ática, pág. 24/5) }\end{array}$} & $\begin{array}{l}\text { Enfoque na questão de que as idéias apropriadas pelos } \\
\text { indivíduos são construções sócio-histórico-culturais. } \\
\text { Propõe uma reflexão sobre permanências na relação } \\
\text { presente/passado. }\end{array}$ \\
\hline & $\begin{array}{l}\text { Aspectos lingüísticos: } \\
\text { É um texto que possui uma linguagem formal, } \\
\text { assemelhada àquela dos livros didáticos com o qual os } \\
\text { estudantes estão familiarizados. } 0 \text { argumento assume } \\
\text { prioritariamente a forma de uma "explicação" } \\
\text {,conduzindo a uma conclusão. } \\
\text { Há marcadores temporais conduzindo a narrativa } \\
\text { ("Hoje em dia", "No século XIX"). }\end{array}$ \\
\hline
\end{tabular}

Na terceira e última sessão, realizada após alguns dias da segunda, os estudantes foram convidados a retomar P1 e reescrevê-la à luz de uma nova leitura e daquilo que havia the chamado a atenção no debate realizado na sessão anterior. Essa produção foi chamada de $P 2$.

É importante ressaltar que, no âmbito do presente estudo, quando apresentamos a proposta de produção escrita aos estudantes, não pretendíamos 
"medir" os conhecimentos históricos que possuíam. O objetivo foi instaurar um espaço de trabalho lingüístico em meio ao qual pudéssemos ter acesso a fragmentos da consciência histórica do sujeito.

Uma vez que nosso objetivo era o de estudar a relação entre consciência histórica e língua escrita, interessava-nos, além de apreender aspectos da consciência histórica do sujeito, perceber movimentos de transformação lingüística e temática em diferentes produções, tanto na escrita, quanto na reescrita. Assim, nossa hipótese centrou-se na idéia de que era nesse espaço constitutivo, mediado pela linguagem, que a consciência poderia se transformar. $\mathrm{Na}$ análise das produções esperava-se colher indícios dos processos reflexivos em torno da língua envolvidos diretamente com essa transformação, indicando um movimento simultâneo de desenvolvimento na expressão e formalização da escrita. Dessa forma, a análise que ora se propõe toma como base os seguintes questionamentos:

1) Que elementos do trabalho lingüístico operado pelos estudantes, aliados à ampliação de sua competência narrativa, permitem-nos entrever fragmentos da consciência histórica?

2) Como o trabalho de reescrita favoreceu a expressão de mais fragmentos da consciência histórica, indicando seu desenvolvimento ou sua eventual transformação?

Na comparação entre P1 e P2, percebemos a recorrência de algumas estratégias adotadas pelos estudantes. Esses movimentos mostraram-se peculiares e revelaram um processo significativo de apropriação dos modelos de dizer e dos conteúdos temáticos apresentados no momento de ampliação da reflexão lingüística e bistórica que antecedeu P2. Essas recorrências, organizadas em categorias, tornam possível o mapeamento de algumas características da relação que ora procuramos desvelar. Assim, no conjunto das produções escritas dos estudantes (P1 e P2), ganhou corpo aquilo que convencionamos chamar de estratégias globais de reescrita, caracterizadas por movimentos estruturais, discursivos e temáticos que configuram a diferença (e por que não dizer, o avanço) de P1 para P2. Com base nessas estratégias, foi possível identificar três grandes categorias: Eliminação, Inserção e Novo Texto.

Estreitamente vinculados às estratégias globais, identificamos também movimentos no interior dos textos, configurando as operações lingüísticas que se corporificam no processo de reescrita, tais como a supressão, o 
deslocamento, a adição e a substituição, já apontadas por outros estudos sobre a reescrita (FIAD, 1990).

A supressão, que pressupõe a elaboração e o uso de critérios de seleção por parte do sujeito-autor, ocorreu quando palavras, frases ou parágrafos foram retirados de uma produção para outra. Em alguns casos, os estudantes inseriram novas estruturas no lugar, em outros, houve apenas a eliminação da formulação original. Quando o estudante mudou o lugar de palavras, frases ou parágrafos inteiros, ele operou o deslocamento, cuja utilização pôde demonstrar o trabalho com a categorização do que estava sendo escrito e/ou com a progressão temática do texto. A adição materializou-se pela inserção de novos dados, informações ou idéias que não existiam na primeira versão da produção. Ela ocorreu em palavras ou pequenos trechos inseridos em frases ou parágrafos. A substituição foi caracterizada pelo movimento em que o autor se colocou de outro lugar no texto. Assim, ele operou mudanças no tempo verbal ou do "eu" para o "nós". Consideramos também como substituição a operação em que o sujeito substituiu em P2 um trecho, uma frase ou um termo por um conjunto de termos correspondentes que podem implicar uma categorização ou uma melhor expressão do que foi escrito em P1. Assim, diferentemente das operações de supressão, quando seguida da adição, os trechos substituídos mantinha relações de significado entre si.

É importante ressaltar que uma série de outras operações lingüísticas ocorreu no interior dos textos. No entanto, escolhemos enfocar aquelas que se configuram no âmbito do processo de reescrita, porque elas nos permitiram caracterizar as transformações operadas a partir de cada estratégia global adotada. A relação entre as estratégias globais (e suas subcategorias) e as operações lingüísticas no processo de reescrita, tal como foram encontradas no corpus da pesquisa, podem ser sintetizadas no seguinte quadro: 
Quadro 3: Categorias de Estratégias Globais e Operações Lingüísticas presentes na reescrita

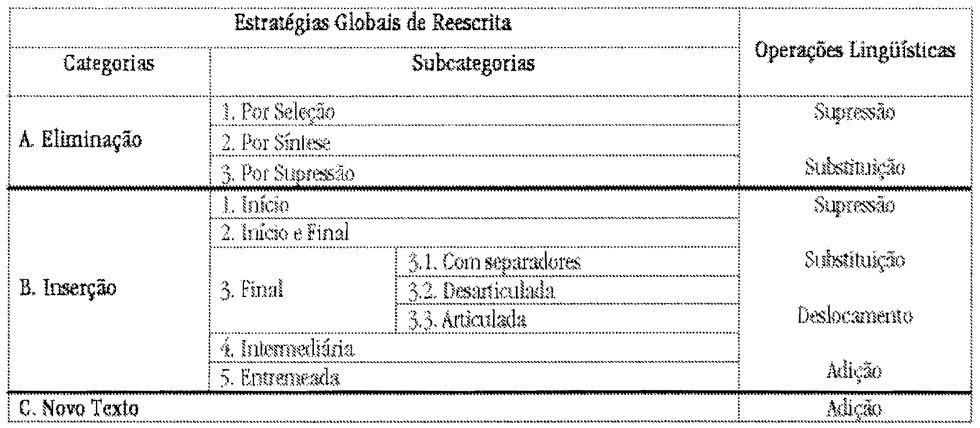

No espaço deste artigo, escolhemos apresentar a análise de um exemplar por categoria (Eliminação, Inserção e Novo Texto).

$\mathrm{Na}$ análise das produções adotamos o paradigma indiciário proposto por GUINZBURG (1989) o qual nos permitiu, através de pistas, indícios, "sintomas", constituir uma análise ajustada aos propósitos da pesquisa. A partir de dados aparentemente negligenciáveis, foi possível vislumbrar aspectos da consciência histórica, que, no seu conjunto, são inatingíveis. 0 trabalho com indícios parece legitimado, principalmente, pelo fato de que a linguagem faz parte de um sistema de comunicação que se estabelece entre interlocutores, numa alternância das falas (ABAURRE, FIAD \& MAYRINK-SABINSON, 1997). As reelaborações e generalizações indicaram-nos movimentos dos sujeitos em constituição e possibilitaram, através das formas pelas quais eles se relacionam com o tempo na escrita, levantar hipóteses sobre as características da relação entre língua escrita e consciência histórica.

\section{A) Estratégias de Eliminação}

A estratégia de Eliminação pode ser explicada, na prática, pela redução do tamanho de P1 a partir de algum critério estabelecido pelo autor. Em nosso corpus encontramos apenas três exemplares que demonstram, respectivamente, maneiras diferenciadas de lidar com a tarefa: por seleção, por síntese e por supressão. Para esse artigo, apresentaremos o exemplar da Eliminação por Síntese 3 . 


\section{Eliminação Por Síntese}

A estudante utilizou-se basicamente de movimentos que resultaram na síntese do que havia sido escrito em P1:

Quadro 4 - Estratégia Global Eliminação - Conjunto 28.8.

\begin{tabular}{|c|c|}
\hline PRODUÇÃO 1 & PRODUÇÃO 2 \\
\hline $\begin{array}{l}\text { Bem eu já presenciei aconteceu com uma amiga } \\
\text { minha. Agente estavamos andando na rua quando } \\
\text { algus meninos comesaram a chamar ela de feijão preto } \\
\text { só porque ela era negra e ela ficou munto mal. Isso } \\
\text { acontece por causa do preconceito e por que algumas } \\
\text { pessoas não si importam com isso e comesão a tirar } \\
\text { saro e tambem por que os pais tenhe preconceito e } \\
\text { também a pessoa não toma atitudi. Já tentaram } \\
\text { melhorar mais algumas pessoas não respeitam em tam } \\
\text { eu acho que cada um deveria respeitar essas pessoas } \\
\text { de cor diferente pois se fosse com elas elas não } \\
\text { iriam costar. }\end{array}$ & $\begin{array}{l}\text { RESUMO } \\
\text { Bom eu já presenciei aconteceu com uma amiga } \\
\text { que foi vitima do racismo eu acho que ser necra ou } \\
\text { não isso não da/o/direito de qualquer pessoa faltar } \\
\text { com o respeito com a outra só por causa da cor. } \\
\text { Bom o que era para ser feito o governo já féis o } \\
\text { importante é as pessoas colaborarem ou ceja } \\
\text { respeitar as pessoas necras pois se foçe com elas. } \\
\text { (elas) não iriam gostar }\end{array}$ \\
\hline
\end{tabular}

Para a autora do conjunto 28.8, a Eliminação significou realizar algumas supressões. A própria estudante chama P2 de "resumo", provavelmente avisando ao leitor que produzirá um texto menor do que aquele que foi escrito em P1. A primeira modificação ocorre por uma operação de substituição em que a situação vivida ("Agente estavamos andando na rua quando algus meninos comesaram a chamar ela de feijão preto só porque ela era negra e ela ficou munto mal") foi sintetizada ("uma amiga que foi vítima de racismo"). Nessa transformação, a estudante nomeou o que havia sido vivido pela amiga e narrado por ela, dando indícios de uma operação cognitiva de generalização.

Num outro trecho, ela novamente se utiliza da substituição: de "respeitar essas pessoas de cor diferente" ( $\mathrm{P} 1)$, passa para "respeitar aspessoas necras..." (P2). Embora em termos sociológicos, no Brasil, as duas palavras sejam consideradas equivalentes, a mudança operada pela estudante aponta para

3 É interessante registrar o baixo número de produções centradas nas estratégias de Eliminação, contrariando discursos recorrentes na escola de que os estudantes escrevem menos por "preguiça". Nos três trabalhos analisados há indícios de um trabalho lingüístico operado com intencionalidade discursiva, o que descarta a hipótese de supressões operadas ao acaso. 
uma reflexão sobre as formas pelas quais os textos e os discursos do cotidiano se referem aos afro-descendentes.

Na parte final, mais uma vez a estudante utilizou-se da supressão, eliminando em P1 o trecho onde explicava os condicionantes da discriminação racial ("ISso acontece por causa do preconceito e por que algumas pessoas não si importam com isso e comesão a tirar saro e tambem por que os pais tenhe preconceito e também a pessoa não toma atitudi.") e o substitui por uma crítica ao comportamento das pessoas que discriminam ("eu acho que ser necra ou não isso não da/o/direito de qualquer pessoa faltar com o respeito com a outra só por causa da cor"). Se considerarmos que, para a estudante, $\mathrm{P} 2$ deveria necessariamente ser menor que P1, naturalmente um critério de escolha foi elaborado. Para ela, a necessidade de marcar sua posição contra o que havia acontecido com a amiga pareceu mais relevante que a explicação sobre as razões do episódio.

Por último, é interessante observar que a primeira e a última frase são mantidas ("Bom eu já presenciei aconteceu com uma amiga..."; "...ceja respeitar as pessoas necras pois se foçe com elas. (elas) não iriam gostar"), como se fossem marcadores indispensáveis. Pareceu-nos que a aluna garantiu a sua permanência por entender as referidas sentenças como dispositivos necessários na estrutura do texto.

Mesmo sem a ampliação da idéia, devido às supressões sem correspondente adição, as estratégias utilizadas por dois desses estudantes revelaram operações lingüísticas de supressão e substituição como forma de ajuste da estrutura textual na reescrita, realizado por meio de operações cognitivas de generalização, categorização e síntese. Parece-nos que a estratégia global de Eliminação potencializa, prioritariamente, este tipo de processo em detrimento de uma maior explicitação de fragmentos da consciência histórica.

\section{B) Estratégias de Inserção}

A diversidade de subcategorias e de operações lingüísticas (em particular a de adição que foi predominante) encontradas nesse grupo indica os esforços dos estudantes na busca de ampliar os sentidos a partir do momento de ampliação.

No corpus desse trabalho, identificamos 5 Estratégias Globais de Inserção: 
no início do texto (Início); no início e no final simultaneamente (Início e Final); somente no final (Final); um bloco no meio do texto (Intermediária) e, por último, em diversos pontos da produção (Entremeada). Apresentamos aqui a análise de um dos casos de Inserção Início e Final.

Inserção: Início e Final

Essa forma de inserção, da qual tivemos 4 ocorrências, é aquela em que novas informações e idéias aparecem, simultaneamente, no início e no final do texto. 0 conjunto que segue foi o escolhido para exemplificar essa categoria:

Quadro 5: Categoria Início e Final - Conjunto 31.8.

\begin{tabular}{|c|c|}
\hline PRODLCAOO 1 & PRODUCĀO 2 \\
\hline $\begin{array}{l}\text { Bom eu já presenciei um homem } \\
\text { chamar o outro de macaco durante } \\
\text { uma discurção de visinhos. Isto } \\
\text { acontece por causa do preconceito, } \\
\text { que é gerado muitas vezes por } \\
\text { familiares que tem costume de } \\
\text { chama alguem por sertos nomes, } \\
\text { seus filhos ao ver isto acabam } \\
\text { achado uma coisa normal, e } \\
\text { acabam crescendo e virando } \\
\text { adultos preconceituosos sem saber. } \\
\text { Para acabarmos com isso } \\
\text { precisamos de leis mais rigidas, } \\
\text { maiores punições, e tambem que } \\
\text { as pessoas que sofem preconceito } \\
\text { no trabalho, no transito, no dia-a- } \\
\text { dia tome atitudes coretas como } \\
\text { denunciar. }\end{array}$ & $\begin{array}{l}\text { Des do fim da escravidão até hoje o negro não tem oportunidades } \\
\text { na sociedade, e tambem sofrem preconceito racial. } \\
\text { Bom eu já presenciei um homem chamar o outro de macaco } \\
\text { durante uma discurção de visinhos. Isto acontece por causa } \\
\text { do preconceito, que muitas vezes é gerado por familiares que } \\
\text { tem costume de chamar alguem por sertos nomes, seus filhos } \\
\text { a ver isto acabam crescendo e virando adultos } \\
\text { preconceituosos sem saber. } \\
\text { Para acabarmos com isso precisamos de leis mais rigidas, } \\
\text { punições mais rigorosas, e que as pessoas que sofrem } \\
\text { preconceito no trabalho, no transito, no dia-a-dia, tome } \\
\text { atitudes coretas como denunciar. O governo deveria interferir } \\
\text { neste tipo de cituação, o governo deveria criar leis mais ceveras e } \\
\text { punições mais rigorosas. } \\
\text { As escolas diviam passar aos alunos um melhor conceito de } \\
\text { educação, não só contra o preconceito racial mas também outros } \\
\text { tipos de preconceito por exemplo: o preconceito sobre } \\
\text { homossexuais, etc. } \\
\text { Este conceito de educação deve ser encinado no primário com } \\
\text { filmes infantis, teatros, etc. } \\
\text { Ainda hoje existe um preconceito sobre a favela, que lá so tem } \\
\text { drogrados, gente que passa fome, baracos,. Mas isto não é a } \\
\text { realidade porque na favela tem cultura, arte, e casas de cimento, e } \\
\text { nem todo mundo passa fome ou esta mal vestido, e nem todo } \\
\text { mundo usa drogas. } \\
\text { "Eu espero que um dia não exista nenhum tipo de preconceito." }\end{array}$ \\
\hline
\end{tabular}

Em 31.8, o passado remoto é inserido pela estudante no início de P2 ("Des do fim da escravidão..."), seguido pelo relato da situação presenciada num passado mais recente ("eu já presenciei um homem chamar o outro de 
macaco..."), para, a partir daí, introduzir considerações sobre o que poderia ser feito no futuro. 0 presente é apresentado pelo enfoque da existência de diferentes modalidades de preconceito, e a autora exemplifica, discorrendo sobre a visão que a sociedade tem da favela. É interessante observar que a estudante esforçou-se para explicitar várias dimensões da reflexão. Além disso, preocupa-se com a progressão temática do texto, evidente no comentário sobre o presente: primeiro, aborda o preconceito racial, preocupando-se com a evolução temporal na constituição da narrativa (passado-presente-futuro), para, em seguida, tecer considerações sobre outro tipo de preconceito.

Em P1, a relação com o passado é determinada pela busca de semelhanças entre a situação do jogador Grafite e aquela presenciada pela autora. Essa operação é mantida em P2, e a ela é agregada a busca de continuidades, referindo-se ao fim da escravidão como início do processo de exclusão social do negro.

Nesse conjunto também é possível visualizar o uso de operações de deslocamento na busca de melhor expressão, como podemos observar abaixo:

Em P1: Isto acontece por causa do preconceito, que é gerado muitas vezes por familiares

Em P2: Isto acontece por causa do preconceito, que muitas vezes é gerado por familiares.

É importante ressaltar que esse tipo de deslocamento apareceu com certa freqüência nas produções dos estudantes em todas as categorias, aparentemente indicando preocupação de ordem estilística, a serviço das intenções discursivas.

As produções de 31.8 indicam ganhos reflexivos e ampliação de elementos na relação passado/presente. Daí emergem fragmentos indicativos de uma consciência histórica crítica, que transparece pela problematização de valores sociais arraigados.

A estratégia de inserção Início e Final parece configurar-se como um espaço propício à reflexão, por forçar a construção de um todo coerente e melhor articulado na construção do argumento. Os estudantes que utilizaram essa estratégia global de reescrita tiveram oportunidades de reflexão tanto no aspecto lingüístico - por alguns deslocamentos realizados ou ajustes no 
encadeamento da narrativa -, quanto naquele referente à consciência histórica. Ao serem envolvidos em uma prática discursiva, ou seja, ao realizarem operações de e sobre a linguagem, os sujeitos ampliaram sua competência linguística de forma a poder organizar, reorganizar e sistematizar seus conhecimentos históricos. Identificamos claros indícios de ampliação da competência narrativa. Nesse sentido, podemos afirmar que o esforço em incorporar maneiras de dizer é correlato àquele de compreender mecanismos envolvidos com a temática em questão que podem promover o desenvolvimento da consciência histórica.

\section{C) Novo Texto}

Além dessas operações em que os estudantes apóiam-se em P1 trazendoa para P2 e operando adições, substituições, deslocamentos e supressões, encontramos um terceiro grupo, composto por produções de 7 estudantes, onde o sujeito-autor elabora um texto totalmente novo. A estratégia global de reescrita Novo Texto surge por um movimento que, em alguns casos, resultou na transformação da opinião ou da representação que o estudante possuía antes do momento de ampliação da reflexão lingüística e bistórica. 0 conjunto a seguir é um dos exemplos escolhidos para ilustrar algumas das características da categoria:

\section{Quadro 6: Categoria Novo Texto - Conjunto 13.5.}

\begin{tabular}{|c|c|}
\hline PRODUÇATO 1 & PRODUÇÃO 2 \\
\hline $\begin{array}{l}\text { Um dia jáaconteceu com meu irmão. } \\
\text { Nós estavamos passeando e derrepente um homem } \\
\text { para e fala: } \\
\text { — AI NEGRINHO DO PASTOREIO fica parado ai } \\
\text { mesmo. Ai meu irmão chamou minha mãe e minha } \\
\text { mãe resolveu. } \\
\text { Eu acho que tem que ligar pra policia e deixa que ela } \\
\text { resolva. } \\
\text { Por que eles são idiotas e ficha chingando os soutros } \\
\text { de neguinho. }\end{array}$ & $\begin{array}{l}\text { Na novela rebelde não tem nenhum negro só tem } \\
\text { branco isso é um preconceito. Nos estados unidos eles } \\
\text { são muito preconceituosos também por que eles } \\
\text { separam tudo por exemplo: onibus para branco e } \\
\text { onibus para negro. Aquilo que aconteceu con o } \\
\text { Grafite voi um horror mesmo. Eles deveriam fazer } \\
\text { uma nova leia mas essa e pra valer. Quem ficasse } \\
\text { chingando um negro ia ser preso na hora e ia que } \\
\text { pagar } 40 \text { cestas basicas e ia que ficar } 10 \text { anos na } \\
\text { cadeia. } \\
\text { Algumas pessoas dizem que os negros so roubam mas } \\
\text { e mentira que alguns negros são diguinos mas alguns } \\
\text { negros são diguinos de pena. }\end{array}$ \\
\hline
\end{tabular}


Uma das características que mais chama a atenção nesse conjunto é a supressão do relato pessoal apresentado em P1. Um outro aspecto relacionado a este é o papel que o relato pessoal assume nos textos.

Em P1, todo o percurso da produção demonstra que o "guia" da reflexão foi a estrutura da narrativa, como demonstram os trechos a seguir:

P1 - Relato:

Ai meu irmão chamou minha mãe e minha mãe resolveu.

Corresponde em P1 à reflexão sobre o que é possível fazer nesse tipo de situação:

Eu acho que tem que ligar pra policia e deixa que ela resolva.

P1 - Relato:

Nós estavamos passeando e derrepente um homem para e fala:

- AI NEGRINHO DO PASTOREIO fica parado ai mesmo.

Corresponde em P1 à reflexão sobre por que situações como essa ocorrem: Por que eles são idiotas e ficha chingando os soutros de neguinho.

Em P2, do relato pessoal, a estudante passa para o relato de exemplos ilustrativos, a partir dos quais ela vai configurando o que entende como preconceito ("Na novela rebelde não tem nenhum negro isso é um preconceito."; "Nos estados unidos eles são muito preconceituosos também por que eles separam tudo por exemplo..."). A concretude, que antes era garantida pelo seu relato pessoal, é mantida em P2 por exemplos independentes da esfera vivida.

0 relato, ao tornar concreto um pensamento difuso, possibilita que o sujeito se relacione com a idéia de maneira mais consciente. Uma vez colocada essa possibilidade, ensaia-se uma primeira reflexão que dá abertura a um processo cognitivo de generalização e abstração. É o que torna possível o abandono do relato dos episódios pessoais em benefício de análises mais abrangentes, fazendo referências a questões políticas, econômicas, sociais ou históricas.

No conjunto 13.5, é possível visualizar um ganho reflexivo de P1 para P2 promovido pelo abandono do relato. A justificativa do preconceito, que em P1 foi construída com base em uma situação particular ("Por que eles são 
idiotas..."), amplia-se para o social pela incorporação de condicionantes sociais ("Na novela rebelde..."; "Eles deveriam fazer uma nova lei..."; "Algumas pessoas dizem..."). 0 mesmo processo de generalização já reconhecido em outras produções aparece aqui como a tônica de toda a P2.

0 período que aparece no último parágrafo - um pouco mais confuso, em que as afirmações ficam contraditórias e a compreensão um pouco mais difícil ("Algumas pessoas dizem que os negros so roubam mas e mentira que alguns negros são diguinos mas alguns negros são diguinos de pena."), pode ser entendido como uma tentativa de desligamento da estrutura guiada pelos exemplos, ensaiada pela estudante, na busca de uma análise independente das situações mais pontuais.

A maneira de se utilizar do relato, conforme descrevemos acima, foi observada em 9 produções de todo o corpus, sendo 6 da $5^{\text {a }}$ série e 3 da $8^{\text {a }}$ série, indicando que esse mecanismo é mais utilizado pelas crianças na fase inicial da escolaridade.

A diferença básica da estratégia global Novo Texto, em relação às anteriores, não está só nas possibilidades de generalização que oferece, mas também no fato de que a relação com $\mathrm{P} 1$ estabelece-se em patamares diferentes. Em todas as estratégias globais, percebemos uma relação muito explícita estabelecida entre P1 e P2 centrada nos aspectos formais (cópias, substituições, supressões e adições de partes de $\mathrm{P} 1 \mathrm{em} \mathrm{P} 2$, ou a produção de uma continuação de P1). No caso da estratégia Novo Texto, há uma independência formal entre P1 e P2 já que os textos são completamente diferentes entre si. Trata-se, porém, de uma independência apenas aparente já que os estudantes constroem suas reflexões em P2 com base no que foi feito em P1. Nesse processo, tal como foi apontado nas estratégias anteriores, o texto construído em P1 aparece como um disparador na consideração da questão, um ponto de apoio do qual a reflexão em P2 se desenvolve e se aprofunda. 0 estudante começa a ensaiar um posicionamento progressivamente independente dos fatos concretos e subjetivos, descolando-se gradativamente da estrutura sugerida pela consigna.

Outra característica marcante dessa estratégia global em relação às demais é a possibilidade de associar a estratégia de Novo Texto a uma grande operação de adição, tendo-se em vista que a temática central é mantida, havendo uma relação processual entre P1 e P2. 


\section{Algumas considerações finais}

A análise apresentada procurou demonstrar que, ao se utilizar da língua escrita para produzir seus discursos, os estudantes lançaram mão de uma série de estratégias e operações discursivas. Reorganizações de vários níveis foram percebidas nos textos em busca de uma melhora na expressão aliadas à inserção de dados e idéias que surgiram após o momento de ampliação. Algumas transformações nas produções trouxeram indícios de operações da competência narrativa e, nesse sentido, apontaram para a emergência de novos fragmentos da consciência histórica. Em alguns casos, o contato do estudante com esses fragmentos num contexto mediado pela escrita potencializou o desenvolvimento da consciência histórica.

Foi possível perceber que, na maior parte dos textos, as estratégias globais e as operações lingüísticas que os estudantes lançaram mão tinham a intenção de atribuir sentido a seus discursos, buscando alternativas para o dizer na composição de seu trabalho.

A principal conclusão que se pode extrair da análise das produções escritas dos estudantes é a relação imbricada entre a aprendizagem da língua escrita e 0 desenvolvimento da consciência histórica. No processo de reescrita, após um percurso reflexivo motivado por leitura e debate de textos, dois movimentos foram claramente percebidos. Um primeiro, relacionado à explicitação de mais fragmentos da consciência histórica do estudante pela ampliação das possibilidades de dizer. 0 contato com novas informações e formas de dizer favoreceu a emergência de idéias e o estabelecimento de relações que não estavam evidentes inicialmente. E, nesse sentido, além da consideração de mais aspectos no discurso do aluno, o diálogo mediado que lhe foi permitido, em alguns casos, potencializou a transformação da sua forma de pensar. A expansão dos modos de dizer esteve, portanto, estreitamente relacionada a um processo em que o estudante evidenciava, nas operações da competência narrativa (experiência, orientação e interpretação), sua maneira de compreender o tempo.

O outro movimento deixa evidente, simultaneamente, que, a potencialização da competência narrativa amplia a possibilidade de aprofundar as reflexões sobre o como dizer. Considerações em diferentes níveis (fonológica, sintática, gramatical e lingüística) foram realizadas pelos estudantes, 
melhorando a expressão da idéia. Constatamos, a partir daí, que a maior explicitação de fragmentos da consciência histórica, evidentes em nosso trabalho pelas maneiras como os estudantes se utilizaram do tempo em suas narrativas, favoreceu as reflexões sobre o sistema de representação da língua escrita.

Investir na aprendizagem da língua escrita no contexto do ensino de História significa potencializar a capacidade do sujeito de refletir sobre o mundo, apropriandose dele e constituindo-se nessa relação. Trata-se de configurar o aprender como experiência no sentido benjaminiano, em que a retomada da capacidade de narrar significa, simultaneamente, operar um deslocamento em que sua humanidade é compreendida no âmbito do coletivo, e que o tempo seja o colo que o recebe, o embala e the permite enxergar novos horizontes. Nesse sentido, língua escrita e consciência histórica não se constituem prioritariamente como objetos isolados que precisam ser apreendidos para tornar o indivíduo capaz de algo a posteriori. A sua aprendizagem integrada sobre essas novas bases já é, em si, o próprio processo de transformação e emancipação.

\section{Referências}

ABAURRE, M. B. M.; FIAD, R. S. \& MAYRINK-SABINSON, M. L. T. (1997) Cenas de aquisição da escrita. Campinas: ALB: Mercado das Letras.

AGUIAR, W. M. J. (2000) Reflexões a partir da psicologia sócio-bistórica sobre a categoria "consciência". In: Cadernos de Pesquisa, n" 110, p. 125-142, julho. BAKHTIN, M. (1986) Marxismo e Filosofia da Linguagem. São Paulo: Hucitec.

CERRI, L. F. (2000) Ensino de História e Nação na Publicidade do Milagre Econômico. (Brasil: 1969-1973). Campinas: UNICAMP/Faculdade de Educação tese de doutoramento.

FIAD, R. S. (1990) Operações lingüísticas presentes nas reescritas de textos. Revista 0 Foco - Lingü̈ista e ensino de línguas. Campinas, janeiro, no. 4.

FIORIN, J. L. (2002) As astúcias da enunciação - As categorias de pessoa, espaço e tempo. São Paulo: Ática.

FREITAS, M.T. de A. (2002) Vygotsky e Bakbtin. São Paulo: Ática.

OLIVEIRA, M. K. de (1993) Vygotsky - Aprendizado e desenvolvimento um processo sócio-bistórico. São Paulo: Scipione. 
OLSON, D. R. (1997) O mundo no papel - implicações conceituais e cognitivas da leitura e da escrita. São Paulo: Ática.

REGO, T. C. (2001) Vygotsky - uma perspectiva sócio-cultural da educação. Petrópolis: Vozes.

RICOUER, P. (1994) Tempo e narrativa. Campinas: Papirus.

RÜSEN, J. The didactics of history in west Germany: towards a new self-awareness of bistorical studies. Em: History and theory. Middletown, nº. 3, oct, p. 275-286, 1987. (vol. XXVI).

El desarrolo de la competencia narrativa en el aprendizaje bistórico. Una hipótesis ontogenética relativa a la conciencia moral. Revista Propuesta Educativa, no. 7. Buenos Aires: Flacso, (27-36), 1992.

Council,1993.

Study in Metabistory. Pretoria: Human Sciences Research

- El libro de texto ideal - reflexiones entorno a los médios para guiar las clases de bistoria. in: Íber-Didáctica de las Ciencias Sociales, Geografia e Historia, n. 12, pp-79-93, abril, 1997.

Razão bistórica - teoria da bistórica: os fundamentos da ciência bistórica. Brasília: EdUnb, 2001a.

Perda de sentido e construção de sentido no pensamento bistórico na virada do milênio. In: História - debates e tendências. Passo Fundo, v. 2, n. 1, p. 9-22, dezembro, 2001b.

Historical Consciousness: Narrative Structure, Moral Function, and Ontogenetic Development. In: SEIXAS, P. Theorizing Historical Counsciousness. Toronto/Bufalo/Londres: University of Toronto Press. (pp.63-85), 2004.

History: Narration, Interpretation, Orientation. New York, Oxford: Berghahn Books, 2005.

VYGOTSKY, L. S. Pensamento e linguagem. São Paulo: Martins Fontes, 1993. 


\section{Written language and historical consciousness in children and adolescents productions.}

\section{ABSTRACT}

The empiricist conceptions of learning in the teaching of History are centered, mostly, in the transmission of facts and concepts through the exhibition of the content and fixation exercises. In the teaching of the written language, they privilege the domain of the code and of the spelling, being centered more in the structures than in the usage. Opposed to that, the present article bring to us some aspects of the understanding of the cognitive processes involved with development of the historical consciousness and the narrative competence, looking into the reflections of Vygotsky and Bakhtin on the relationship word and consciousness of Rüsen on the historical consciousness as learning. The corpus of the investigation was constituted by 134 textual productions of 67 students (29 of the 5 th grade and 38 of the 8 th grade of the secondary school) of a municipal school of São Paulo. They were invited to writing and rewriting a text considering a social problem.

Key-words: Teaching of written language,Textual production, Teaching of history, Historical consciousness, Didactics of history. 